\title{
Functional and technological properties of food nanoadditive based of double oxide of bi- and trivalent iron in lyophilic colloidal dispersed systems
}

\author{
Iryna Tsykhanovska ${ }^{1}$, Olena Stabnikova ${ }^{2}$, \\ Oleksandr Alexandrov ${ }^{1}$, Roman Trishch ${ }^{1}$, Olga Blagiy $^{\mathbf{1}}$
}

1 - Ukrainian Engineering-Pedagogics Academy, Kharkiv, Ukraine

2 - National University of Food Technologies, Kyiv, Ukraine

Keywords:

Functional

Nanoadditive

Iron oxide

Colloids

\section{Article history: \\ Received \\ 16.04.2021 \\ Received in \\ revised form \\ 21.07.2021 \\ Accepted \\ 30.12.2021}

\section{Corresponding} author:

Olena

Stabnikova

E-mail:

stabstab6@

gmail.com

DOI:

$10.24263 / 2304-$

974X-2021-10-

4-6

\section{Abstract}

Introduction. Magnetofood is food nanoadditive based on double oxide of bi- and trivalent iron. Functional and technological properties of food nanoadditive Magnetofood incorporated in lyophilic colloidal dispersed systems were studied.

Materials and methods. Model systems included food nanoadditive Magnetofood $\left(\mathrm{Fe}_{3} \mathrm{O}_{4}\right)$, water, agar, pectin, and egg albumin. The effective viscosity and thixotropic properties were determined on a rotary viscometer; the strength of the whipped and gel masses was studied by the shear stress; the change in the foam stability was recorded by the settling of the foam column over time.

Results and discussion. Nanoparticles $\mathrm{Fe}_{3} \mathrm{O}_{4}$ of food additive Magnetofood capable to form clusters and exhibit properties of selforganizer caused the formation of electrostatic complexes with proteins and polysaccharides. The thickening, thixotropic, structure-forming, and stabilizing properties of Magnetofood added to lyophilic colloidal systems were studied. Addition of Magnetofood into lyophilic colloidal systems increases the viscosity of foam systems in 1.10-1.15 times, gel systems with agar in 1.22-1.27 times and gel systems with pectin in 1.24-1.29 times. This also slows down the destruction processes in gel structures in 1.15-1.22 times and accelerates the processes of their recovery after termination of mechanical action by $8.8-9.2 \%$, increasing their ability to thixotropy in 1.4-1.5 times. Determination of the ultimate shear stress of colloidal-dispersed systems showed that an addition of Magnetofood to lyophilic colloidal systems increases mechanical strength of foam systems with agar by $11.5-12.6 \%$ and with pectin by $8.2-9.1 \%$, of gel systems with agar in 1.32-1.8 times and with pectin in 1.49-1.57 times. Addition of Magnetofood to lyophilic colloidal systems increases the speed of gel structuring in $1.73 \pm 0.01$ times for agar and in $1.67 \pm 0.01$ times for pectin compared with the control and a reduction of the amount of gelling agent by $10.0-12.0 \%$ for agar and by $7.0-9.0 \%$ for pectin. The foaming ability of egg albumin increases $1.14-1.40$ times at constant foam stability $99.0 \pm 1.0 \%$ due to the action of $\mathrm{Fe}_{3} \mathrm{O}_{4}$ nanoparticles.

Conclusions. For the first time, the thickening, thixotropic, structure-forming, stabilizing actions of $\mathrm{Fe}_{3} \mathrm{O}_{4}$ nanoparticles in "lyophilic colloids" were studied to determine the functional and technological properties of food additive Magnetofood. 


\section{Introduction}

Lyophilic colloidal disperse systems are microheterogeneous multi- or polyphasic food systems, often based on high molecular weight compounds such as proteins (egg albumin, gelatin), and polysaccharides (pectin, agar). Therefore, to find the methods to stabilize polyphasic "lyophilic colloids", in particular pastille-marmalade products, is relevant. In addition, in today's conditions of strong competition on the domestic market, producers of pastille and marmalade are looking for ways to increase competitive ability by improving the functional and technological characteristics of raw materials which will cause the increasing of consumer properties, reducing costs, and extending shelf life of the finished products. Novel natural additives such as materials of plant origins are widely used in recent years in preparation of different traditional food products (Stabnikova et al., 2021). Application of non-traditional raw plant materials with various properties are widely used to stabilize the polyphase structure of pastille and marmalade and maintain the quality and storage stability of finished products. These materials include industrial food processing wastes from canning, wine, and sugar beet production, and agricultural wastes from seed-growing farms, cotton growing, and melon cultivation. Alternative raw materials such as chitosan, vegetable and fruit products (Cappa et al., 2015; Shaaban et al., 2020) including puree of feijoa, kiwi, Jerusalem artichoke (Emelike and Akusu, 2019; Silva and Abud, 2017); extracts and powders of spicy aromatic herbs and vegetable, fruit and berry powders (help to improve the consistency and consumption characteristics of the finished product, however their disadvantage is insufficient stability of the gel-like structures) (Moghaddam et al., 2009; Sicari et al., 2017); sorbitol (Dai et al., 2020); hydrocolloids such as carrageenan and its sodium, potassium, ammonium salts, including furcellaran, guar gum, locust bean gum, and xanthan gum (help to increase the moisture holding capacity and improve the elastic properties of pastille-marmalade products for a long shelf life) (Gawkowska et al., 2018; Kambulova et al., 2017; Sanzharovskaya et al., 2017) are used in production of pastille and marmalade. Combined systems of structurants are also widely used, for example combinations of gelatin with high methoxyl pectin (Yang et al., 2013); hydrocolloids (Herbagel SW-010, ricogel 8100); sulphated polysaccharides, or k-carrageenan (Kambulova et al., 2017; Mudgil et al., 2011); agar with concentrate of animal proteins Scanpro (Pertsevoi et al., 2008), and various modifying systems such as sodium carboxymethylcellulose (NaCMC) with ferric chloride (Mudgil et al., 2011); sodium lactate or sodium citrate with glycerin (Sanzharovskaya et al., 2017), protein-polysaccharide composite materials (Bealer et al., 2020), and modification of metal nanoparticles and their oxides with polysaccharides, proteins of plant and animal origin such as egg albumin, gelatin, whey protein, gliadin, legume and soy proteins, elastin, zein, milk protein (Liang et al., 2007; Mousavi et al., 2019; Rana et al., 2019; Verma et al., 2018).

A food nanoadditive Magnetofood based on double oxide of bivalent and trivalent iron with a particle size of the nanometer range from 70 to $80 \mathrm{~nm}$ was proposed (Tsykhanovska et al., 2016). Magnetofood has a chemically active near-surface layer, and is characterized by amphiphilicity with $\zeta$-potential of $33-40 \mathrm{mV}$, which is the basis for its use in the production of food with lyophilic colloidal-dispersed structure, in particular pastillemarmalade products. Addition of Magnetofood corrects the surface activity of structurants and affects the effective viscosity of dispersed systems, which is one of the factors of gel and foam forming. Therefore, nanoadditive Magnetofood is able to correct the structural and mechanical properties of jelly masses and foam-like structures, and interact electrostatically with the structurants such as egg albumin, gelatin, pectin, and agar enhancing their actions. Magnetofood nanoparticles promote the formation of various supramolecular structures: 
monolayers, micelles, which capable to stabilize the polyphasic system of "lyophilic colloids", form certain of gel, and foam consistency (Tsykhanovska, 2019; Tsykhanovska et al., 2019a).

The aim of the present research was to study the influence of food additive Magnetofood on the processes of foaming and gelation in the production of pastille and marmalade.

\section{Materials and methods}

\section{Materials}

Food additive Magnetofood is a fine powder of brown or black colour with a particle size of 70-80 nm. By the chemical composition Magnetofood is double iron oxide, $\mathrm{Fe}_{3} \mathrm{O}_{4}$, which was obtained by the chemical coprecipitation from aqueous solutions of bivalent and trivalent iron salts at alkaline $\mathrm{pH}$ (Tsykhanovska et al., 2016).

Model systems, which used in the study, were: (a) gelling agent (pectin or agar) + Magnetofood; (b) foaming agent (egg albumin) + Magnetofood; (c) egg albumin + agar or highly esterified (HE) pectin + Magnetofood; suspensions of nanoparticles Magnetofood in $5 \%$ aqueous solution of highly esterified (HE) pectin, agar or $10 \%$ egg albumin.

A suspension of nanoparticles in egg albumin solution was obtained by addition of the calculated amount of Magnetofood into 10\% egg albumin solution at a temperature of 18 $20^{\circ} \mathrm{C}$ under constant stirring $2.0-2.2$ turns per second for $3-5$ min followed by holding for 5-7 min.

A suspension of nanoparticles in solution of agar or HE pectin was obtained by addition of the calculated amount of Magnetofood into 5\% solution of polysaccharide at a temperature 55-6 $60^{\circ} \mathrm{C}$ under constant stirring $2.0-2.2$ turns per second for 5-7 min followed by cooling of the mixture to a temperature $18-20{ }^{\circ} \mathrm{C}$ under continuous stirring.

A suspension egg albumin + agar or HE pectin + Magnetofood was obtained by addition of the calculated amount of food additive into $5 \%$ solution of polysaccharide at a temperature of $55-60^{\circ} \mathrm{C}$ under constant stirring $2.0-2.2$ turns per second for 5-7 min followed by cooling the mixture to a temperature $18-20^{\circ} \mathrm{C}$ under continuous stirring, addition of egg albumin powder under continuous stirring for 3-5 min followed by holding for 5-7 min.

\section{Methods}

\section{Rheological properties}

Rheological properties of lyophilic colloidal dispersed systems were estimated by the measurement of the effective viscosity and calculation of the thixotropy coefficient.

The effective viscosity was determined on a rotary viscometer "Reotest-2" in 5\% or $10 \%$ aqueous suspensions of model systems of the structurants (agar, pectin, or egg albumin) at a temperature of $20 \pm 2^{\circ} \mathrm{C}$ according to formula (1):

$$
\eta=\mathrm{k} \cdot \mathrm{U} \cdot \mathrm{T} \cdot \mathrm{A}
$$

where $\eta$ is the effective viscosity, Pa's;

$\mathrm{k}$ is the constant of the measuring node, $\mathrm{Pa} / \mathrm{V}$;

$\mathrm{U}$ is voltage, $\mathrm{B}$;

$\mathrm{T}$ is period of rotation, $\mathrm{s}$; 
A is the shape factor of the measuring unit.

The shear rate was determined by formula (2):

$$
\gamma=1 / \mathrm{T} \cdot \mathrm{A}
$$

where $\gamma$ is the shear rate, $\mathrm{s}^{-1}$.

The thixotropy coefficient was calculated by formula (3):

$$
K_{\text {thix }}=\left(\eta_{\mathrm{rc}} / \eta_{\mathrm{dc}}\right) \cdot 100
$$

where $K_{\text {thix }}$ is thixotropy coefficient, \%;

$\eta_{\mathrm{dc}}$ is the effective viscosity (direct course), Pa's;

$\eta_{\mathrm{rc}}$ is the effective viscosity (reverse course), Pa's.

To determine the thixotropy coefficient the value of viscosity with a minimum and the same shear rate were inserted in formula (3).

Mechanical strength of foam systems and gel masses were expressed through the ultimate shear stress, $\tau, \mathrm{kPa}$, which was determined at a temperature of $20 \pm 2^{\circ} \mathrm{C}$ for foam systems and at $15-25^{\circ} \mathrm{C}$ for gel systems on agar and at $40-75^{\circ} \mathrm{C}$ for gel systems on pectin with an interval of $5^{\circ} \mathrm{C}$ on modified Kargin-Sogolova scales by studying the fracture force (under uniaxial compression).

The test sample was placed on a platform, the position of which was regulated bringing the sample and the punch into a tangential state, loaded scales and fixed the maximum value of load mass that leads to the crushing of the sample. The fracture force was determined by the formula (4):

$$
P_{f}=4 m \cdot g / \pi \cdot d^{2}
$$

where $\mathrm{P}_{\mathrm{f}}$ is the fracture force, $\mathrm{kPa}$;

$\mathrm{m}$ is weight of load, $\mathrm{kg}$;

$\mathrm{g}$ is free fall acceleration, $\mathrm{m} / \mathrm{s}^{2}$;

$\mathrm{d}$ is the diameter of the sample, $\mathrm{m}$;

$\pi$ is coefficient 3.14 .

The rate of structuring of gel masses was determined by formula (5):

where $\mathrm{V}_{\text {str }}$ is the rate of structuring, $\mathrm{kPa} / \mathrm{s}$;

$$
\mathrm{V}_{\text {str }}=\left(\tau_{\max }-\tau_{0}\right) / \mathrm{t}_{\mathrm{str}}
$$

$\tau_{\max }$ is the maximum value of strength, $\mathrm{kPa}$;

$\tau_{0}$ is the initial value of strength, $\mathrm{kPa}$;

$\mathrm{t}_{\text {str }}$ is the duration of structuring, min.

Foaming ability was determined by the Lurie method and calculated by formula (6):

$$
\mathrm{F}_{\mathrm{a}}=\left(\mathrm{V}_{\mathrm{f}} / \mathrm{V}_{\mathrm{s}}\right) \times 100
$$

where $\mathrm{F}_{\mathrm{a}}$ is the foaming ability, $\%$;

$\mathrm{V}_{\mathrm{f}}$ is the volume of foam, $\mathrm{m}^{3}$;

$\mathrm{V}_{\mathrm{s}}$ is the volume of the sample before beating, $\mathrm{m}^{3}$. 
Foam stability was determined as the ratio of the height of the foam column to the total height of the sample, expressed as a percentage after holding for 6 min for foamy systems, and $144 \mathrm{~min}$ for foam systems and calculated by formula (7):

$$
\mathrm{F}_{\mathrm{s}}=\left(\mathrm{H}_{\mathrm{f}} / \mathrm{H}_{0}\right) \times 100
$$

where $\mathrm{F}_{\mathrm{s}}$ is the foam stability, \%;

$\mathrm{H}_{\mathrm{f}}$ is the height of foam, $\mathrm{m}$;

$\mathrm{H}_{0}$ is the initial height of foam, $\mathrm{m}$.

\section{Statistical analysis}

All analyses were performed at least in triplicates, and data were expressed as mean \pm standard deviation. The differences were considered statistically significant with a reliability of $\alpha=0.95$.

\section{Results and discussion}

\section{Influence of Magnetofood addition on the effective viscosity of gel systems}

The dependence of the effective viscosity $(\eta)$ of aqueous solutions of gel systems "gelling agent + Magnetofood" from the content of Magnetofood, \% (w/w), is shown in Figure 1.

Addition of Magnetofood to all gel systems increased the viscosity in the entire range of shear stress: for change of $\gamma$ from 1.5 to $40 \mathrm{~s}^{-1}$ the effective viscosity increased by $1.22-1.27$ times for systems with agar and by 1.24-1.29 times for systems with pectin in comparison with control (Figure 1). This is due to the chemical activity of the structure-forming cations $\mathrm{Fe}^{2+}$ and $\mathrm{Fe}^{3+}$ located on the surface of nanoparticles Magnetofood and their electrostatic interaction with macromolecules of polysaccharides, which resulted in the formation of a spatial grid. The expedient amount of Magnetofood to be added to gel systems is $0.15 \%$ $(\mathrm{w} / \mathrm{w})$, because its further increase has almost no effect on the change in viscosity of gel solutions.

\section{Influence of Magnetofood addition on thixotropic reduction of gel systems}

Analysis of the change of thixotropic reduction coefficient of the primary structure of the aqueous solutions of gelling agents showed an increase in the coefficient of thixotropy, $\mathrm{K}_{\text {thix }}$, on average in 1.4-1.5 times when Magnetofood was added to the system in comparison with control) (Figure 2).

The thixotropic properties of gel-like systems with Magnetofood have been shown. The addition of Magnetofood to aqueous solutions of gelling agents slowed down the destruction processes in 1.15-1.22 times and accelerated the processes of restoration of the gel structure after the cessation of mechanical action by $8.8-9.2 \%$, increasing its ability to thixotropy in 1.4-1.5 times. This is due to the surface-active properties of Magnetofood and their ability to form a certain consistency and stabilize the lyophilic colloidal dispersed system, which prevents its separation (Tsykhanovska, 2019; Tsykhanovska et al., 2019a). 

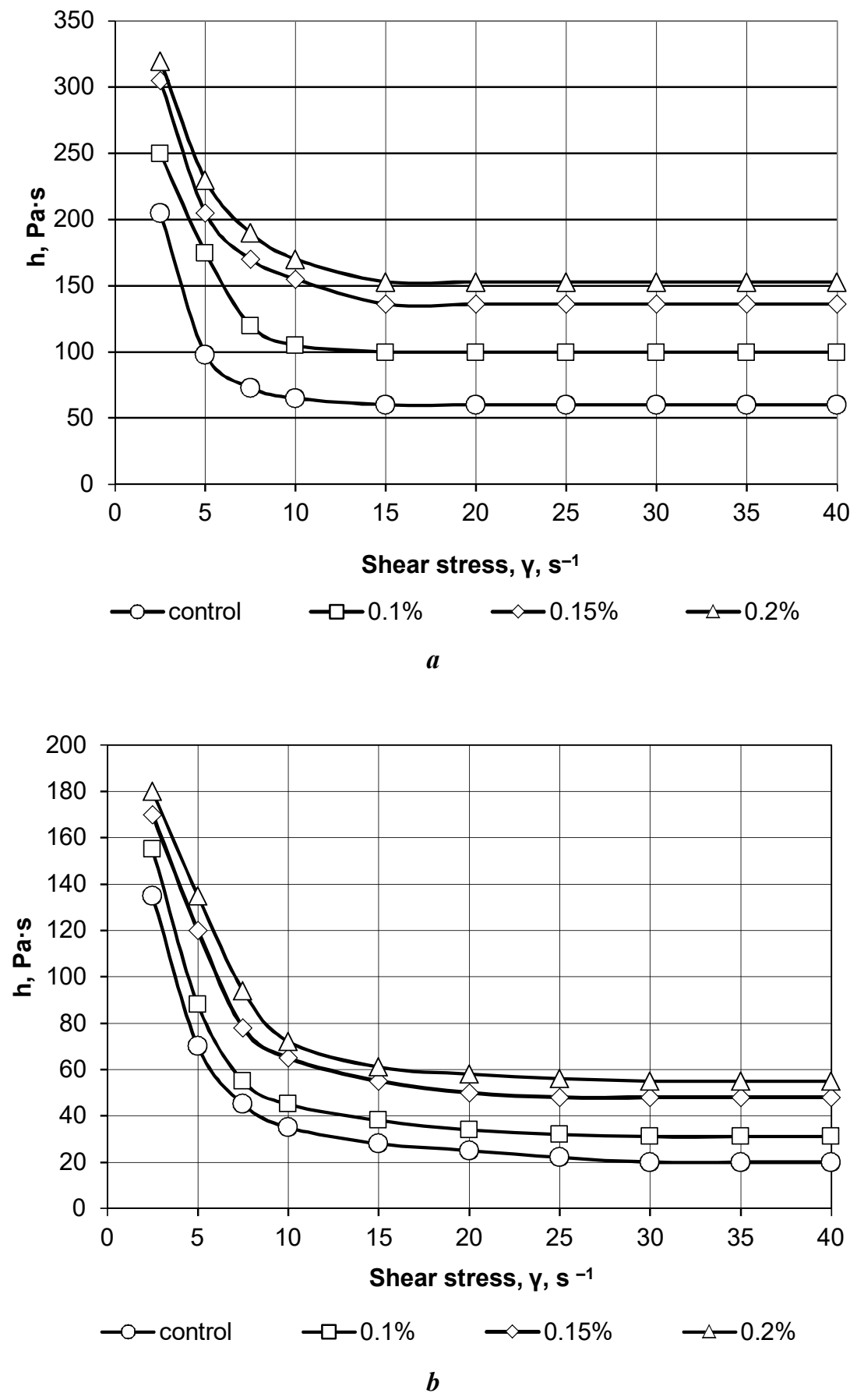

Figure 1. Influence of Magnetofood addition on the effective viscosity of gel systems containing agar $(a)$ and pectin $(b)$ 

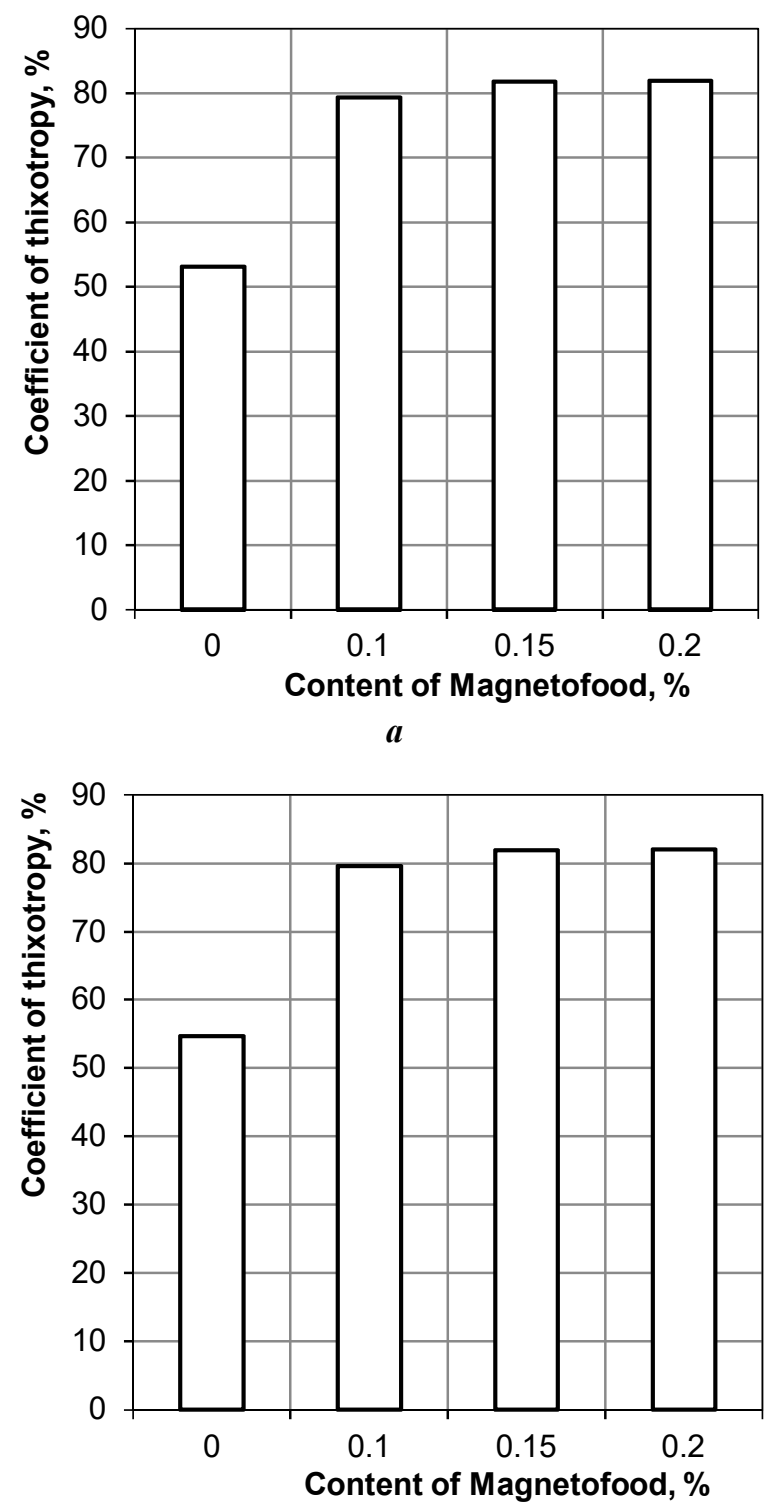

b

Figure 2. Influence of Magnetofood addition on thixotropic reduction of gel systems containing agar (a) and pectin $(b)$ 
Influence of Magnetofood addition on foaming processes and rheological properties of lyophilic colloids

Surface activity and clusterophilicity of Magnetofood can be demonstrated by its influence on foaming processes and rheological properties of lyophilic colloids of egg albumin. Influence of Magnetofood addition in different amounts $0.05,0.10,0.15,0.20 \%$ (w/w of dry egg albumin) on foaming ability $\left(\mathrm{F}_{\mathrm{a}}\right)$ and effective viscosity $(\eta)$ of gel systems "egg albumin + Magnetofood" is shown in Figure 3.

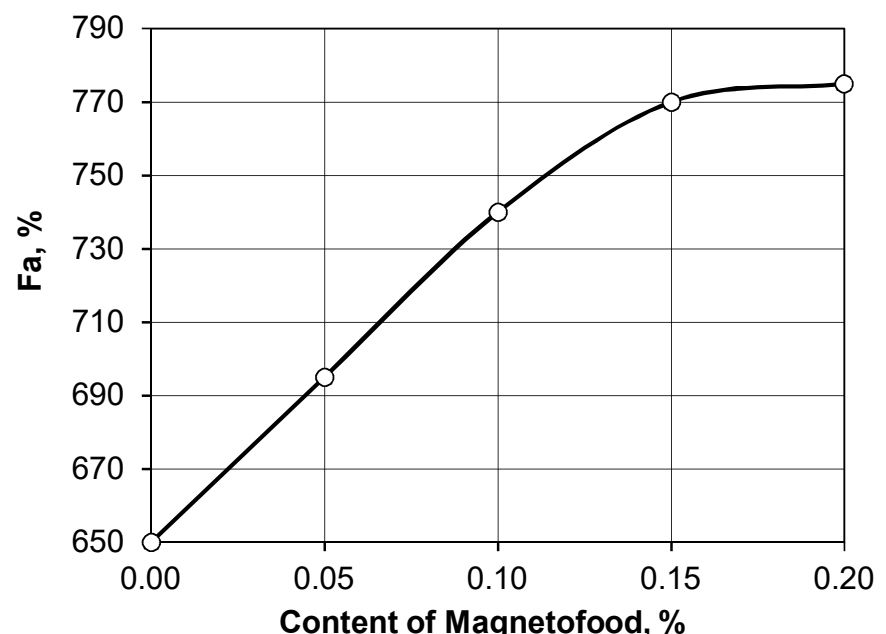

a

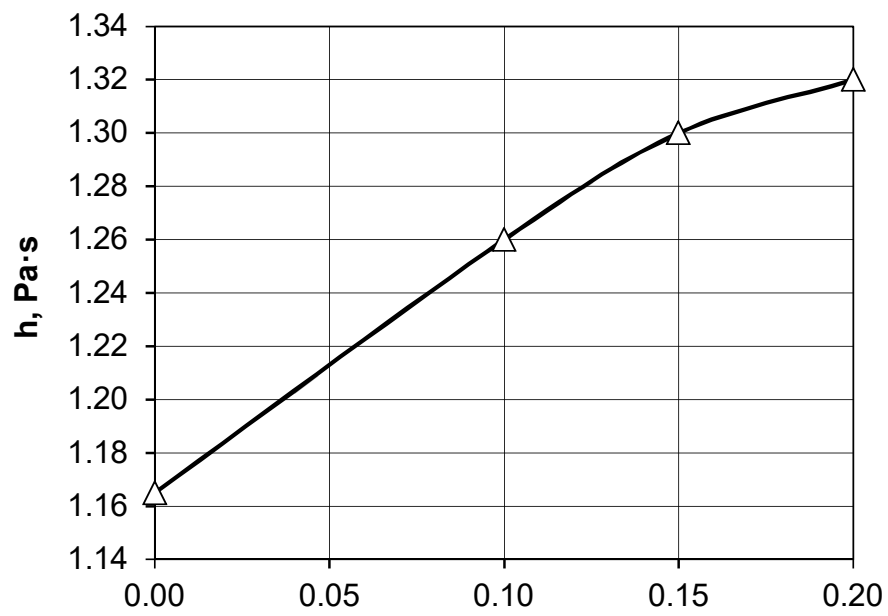

Content of Magnetofood, \%

b

Figure 3. Influence of Magnetofood addition on foam-producing property, $F_{a}, \%,(a)$ and effective viscosity, $\eta, \mathrm{Pa} \cdot \mathrm{s}(\mathrm{b})$ at shear stress $\gamma 4.4 \mathrm{~s}^{-1}$

of gel systems "Egg albumin + Magnetofood". 
The addition of Magnetofood into solution of egg albumin increased its foam-producing property in 1.14-1.19 times compared with control due to reduction of the surface tension of the protein and increased of the rate of coagulation of protein molecules under the action of Magnetofood. This led to an increase in the volume concentration of the air phase in the protein solution and to a decrease of the air bubbles sizes. The foam stability of all systems "egg albumin + Magnetofood" was $99 \pm 1 \%$ because of the stabilizing action of Magnetofood due to the presence of nanoparticles with chemically active surface on the interface of phases in the adsorption layer. This increased cohesion between protein molecules. As a result, the mobility of the liquid decreased, its flow in the film was slowed down, thus preventing the coalescence of foam bubbles. At the same time, the viscosity of the liquid in the foam films increased, which slowed down their destruction and stabilized the foam $\left(\mathrm{F}_{\mathrm{s}}\right)$ at the level of $99 \pm 1 \%$ (Tsykhanovska et al., 2019b). The addition of Magnetofood also increased in 1.10 1.15 times the effective viscosity of the system "egg albumin + Magnetofood" due to electrostatic and coordination interaction of nanoparticles with macromolecules of egg albumin and branching of the main chains of its macromolecules (Figure 3b). Thus, studies of the rheological properties of lyophilic colloidal-dispersed systems (aqueous solutions "gelling agent (agar, pectin) + Magnetofood" and "egg albumin + Magnetofood") confirmed the hypothesis of adjusting these properties of "lyophilic colloids" due to the influence of Magnetofood nanoparticles. The rational amount of Magnetofood addition was determined as $0.15 \%$ by weight of the structurant.

\section{Influence of Magnetofood addition on stability of foam systems}

Changes of the strength, $\tau, \mathrm{kPa}$, of foam systems "egg white + gelling agent + Magnetofood" during 90 min showed that the addition of Magnetofood accelerated the gelation process by $2.0-2.5 \mathrm{~min}$ on agar and by $2.0-2.2 \mathrm{~min}$ on pectin, and increased the maximum shear stress by $11.9-12.6 \%$ on agar and by $8.2-9.1 \%$ on pectin due the formation of supramolecular associates with nanoparticles (Figure 4).

The gel-forming effect of Magnetofood reveals in aggregation of polysaccharides and an increase in the roughness of their channels caused an increase of the stability of the foam films and an increase in the drag-forming ability of pectin and agar. This increases the viscosity in the Gibbs-Plateau channels that leads to stabilization of the gel framework of the foam structure and slows down the process of syneresis. As a result, the process of gel formation is accelerated and the strength of the whipped mass increases.

\section{Influence of Magnetofood addition on ultimate shear stress of gel systems}

Changes of the ultimate shear stress, $\tau, \mathrm{kPa}$, of gel systems" gelling agent + Magnetofood" with the amount of Magnetofood $0.15 \%$ in time is shown in Figure 5.

Addition of Magnetofood increased the strength of the gel system with agar in 1.32-1.8 times and with pectin in 1.49-1.57 times compared to control. 

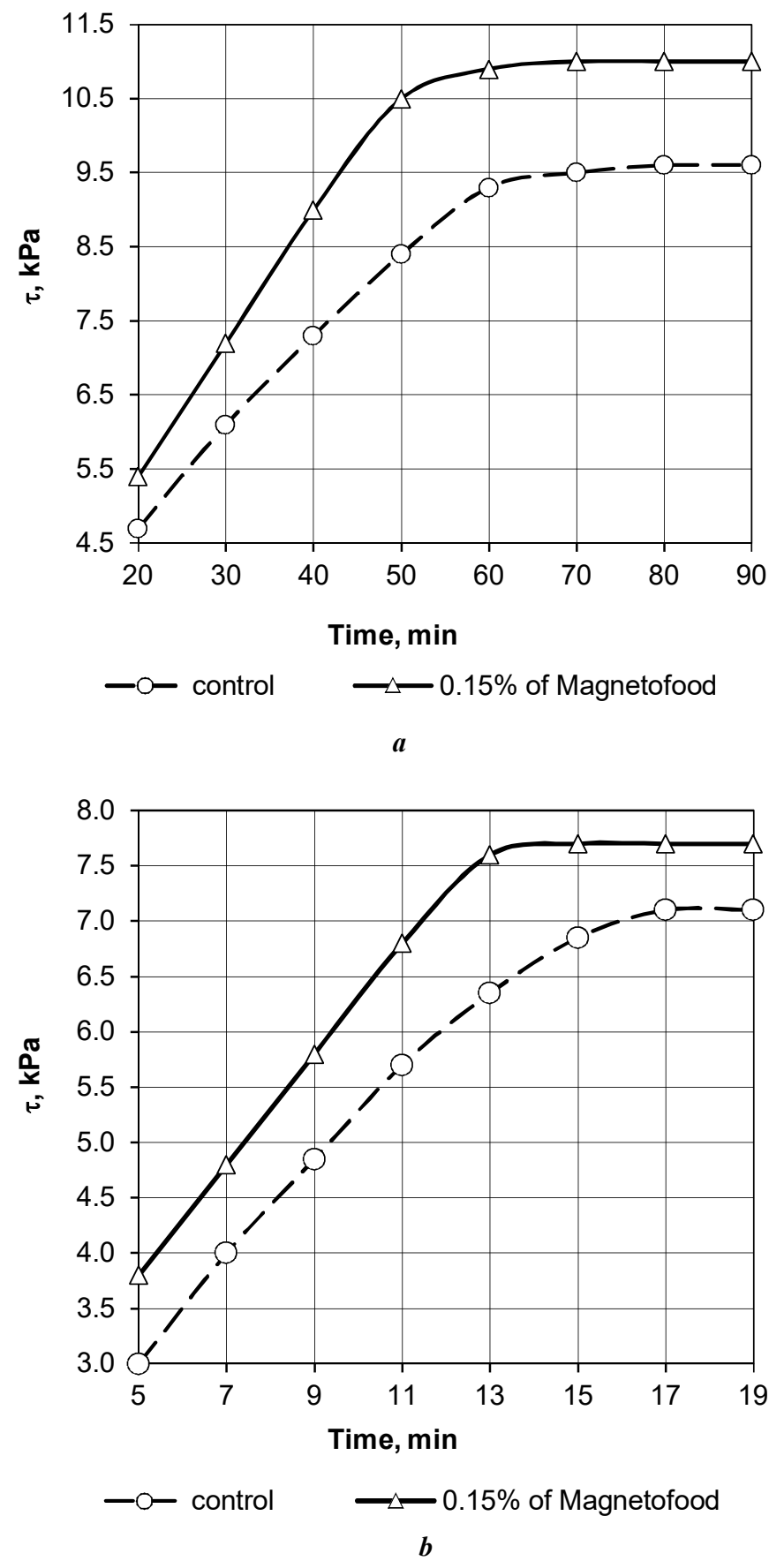

Figure 4. Changes of stability of foam systems "egg albumin + gelling agent + Magnetofood" in time with: $a$ - agar; $b$ - pectin. 


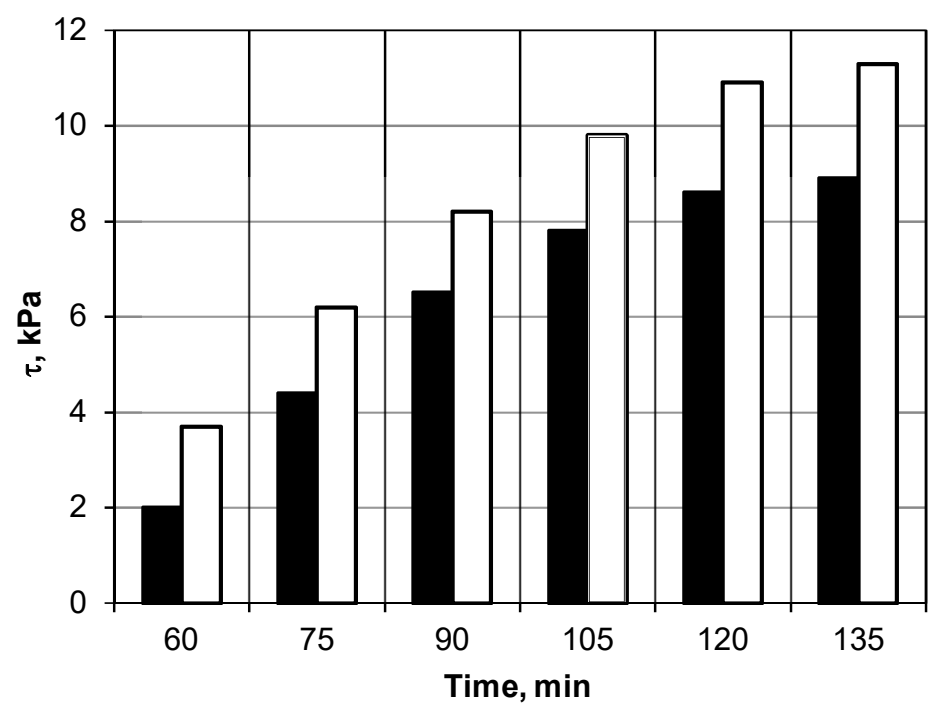

- control $\quad \mathbf{0} 0.15 \%$ of Magnetofood

a

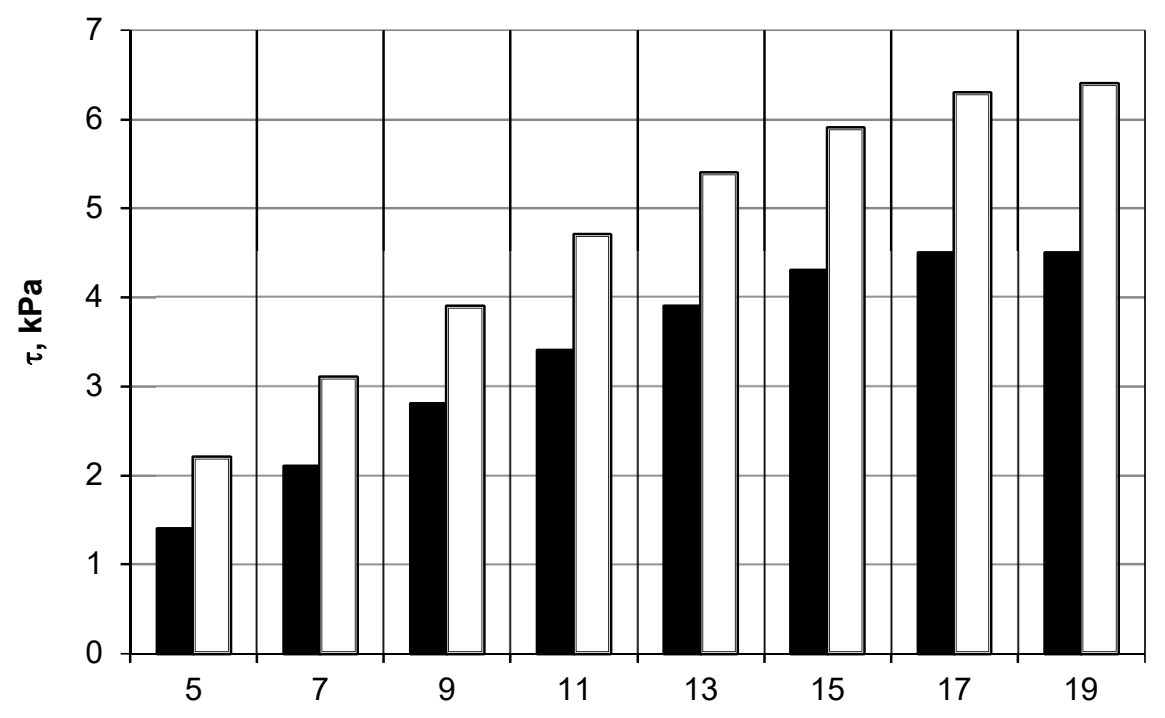

Time, $\min$

-control $\quad \square 0.15 \%$ of Magnetofood

$b$

Figure 5. Changes of the ultimate shear stress of gel systems

"gelling agent + Magnetofood" in time at different temperatures with: $\boldsymbol{a}$ - agar; $\boldsymbol{b}$ - pectin. 


\section{Influence of Magnetofood addition on the rate of structuring of gel masses}

The rate of structuring of gel masses was determined using formula (5) (Figure 6).

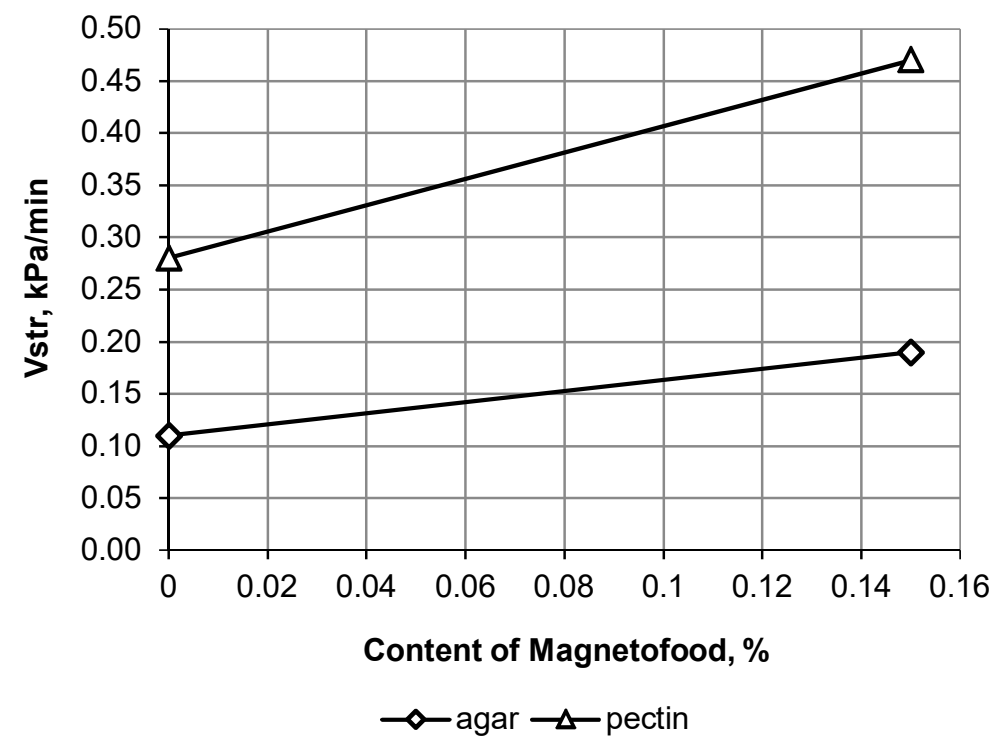

Figure 6. Rate of structuring of gel masses

Addition of Magnetofood leads to an increase of the rate of structuring of gel masses with agar in $1.73 \pm 0.01$ times and with pectin in $1.67 \pm 0.01$ times compared to control. This is due to the ability of Magnetofood to interact with polysaccharides and form an ordered spatial framework that strengthens the gel-like structures. As a result, the formation of a good texture of jelly products having high consumer properties is observed. Additionally, the release of moisture from the products during storage is significantly reduced, so they stay fresh for a longer time. Studies of the structural and mechanical parameters of lyophilic colloidaldispersed systems confirmed the stabilization effect of Magnetofood nanoparticles addition on the polyphasic structure of "lyophilic colloids". Introduction of Magnetofood, $0.15 \%$ by the weight of the structurants, in "lyophilic colloids" allows to reduce the amount of structurants, namely, agar by $9.0-11.0 \%$ and pectin by $7.0-9.0 \%$. It also increases the strength of (a) whipping masses with agar by $11.9-12.6 \%$ and with pectin by $8.2-9.1 \%$ in comparison with control; (b) gel jelly with agar in 1.32-1.80 times and with pectin in 1.491.57 times. Thus, application of food additive Magnetofood accelerates and enhances the processes of structure formation in lyophilic colloidal dispersed systems.

\section{Conclusions}

1. Nanoadditive Magnetofood based on double oxide of bivalent and trivalent iron possesses surface activity and clusterophilicity. 


\section{- Food Technology —}

2. Nanoadditive Magnetofood being added into lyophilic colloid-disperse system accelerates and enhances the processes of its structure formation due to electrostatic and coordination interactions of nanoparticles with macromolecules of egg albumin and polysaccharides.

3. Addition of Magnetofood into the polyphase dispersed system increases its effective viscosity, foaming ability; reduces the speed of structuring; increases the mechanical strength and improves the thixotropic properties of foam and gel systems, which ensured high quality of the final product and extend its shells life.

\section{Recommendations}

The conducted research demonstrated high functional-technological potential of food nanoadditive Magnetofood, which application in technologies of food products with polyphase structure can improve functional-technological properties of heterogeneous dispersed systems and extend shelf life of finished products.

\section{References}

Bealer E.J., Onissema-Karimu S., Rivera-Galletti A., Francis M., Wilkowski J., Cruz D.S., Hu X. (2020), Protein-polysaccharide composite materials: fabrication and applications, Polymers, 12(2), p. 464, DOI: 10.3390/polym12020464.

Cappa C., Lavelli V., Mariotti M. (2015), Fruit candies enriched with grape skin powders: Physicochemical properties. LWT Food Science and Technology, 62, pp. 569-575, DOI: 10.1016/j.lwt.2014.07.039.

Dai H., Li X., Du J., Ma L., Yu Y., Zhou H., Guo T., Zhang Y. Effect of interaction between sorbitol and gelatin on gelatin properties and its mechanism under different citric acid concentrations. Food Hydrocolloids, 2020, 101(4), pp. 105557-105564, DOI: 10.1016/j.foodhyd.2019.105557.

Emelike N.J.T., Akusu O.M. (2019), Quality attributes of jams and marmalades produced from some selected tropical fruits, Journal of Food Processing \& Technology, 10(5), DOI: 10.4172/2157-7110.1000790.

Gawkowska D., Cybulska J., Zdunek A. (2018), Structure-related gelling of pectins and linking with other natural compounds: a review, Polymers (Basel), 10(7), pp. 762-778, DOI: 10.3390/polym10070762.

Kambulova Y.I., Matyas D.I., Malinovsky V.I. (2017), Rheological indicators of marmalade masses on agar and carrageenan and varieties of sugars. Food Industry AIC, 4(46), pp. 19 23.

Liang Y.Y., Zhang L.M., Li, W., Chen R.F. (2007), Polysaccharide-modified iron oxide nanoparticles as an effective magnetic affinity adsorbent for bovine serum albumin, Colloid and Polymer Science, 285, pp. 1193-1199, DOI: 10.1007/s00396-007-1672-2.

Mudgil D., Barak S., Khatkar B.S. (2011), Food additives in confectionery industry: An overview, Indian Food Packer, 65(3), pp. 80-83.

Moghaddam T.M., Razavi S.M.A., Malekzadegan F., Ardekani A.S. (2009), Chemical composition and rheological characterization of pistachio green hull's marmalade. Journal of Texture Studies, 40(4), pp. 390-405, DOI: 10.1111/j.1745-4603.2009.00188.x.

Mousavi S.M., Hashemi S.A., Ramakrishna S., Esmaeili H., Bahrani S., Koosha M., Babapoor A. (2019), Green synthesis of supermagnetic $\mathrm{Fe}_{3} \mathrm{O}_{4}-\mathrm{MgO}$ nanoparticles via Nutmeg essential 
oil toward superior anti-bacterial and anti-fungal performance, Journal of Drug Delivery Science and Technology, 54, 101352, DOI:10.1016/j.jddst.2019.101352.

Pertsevoi F.V., Teimurova A.T., Pohozhykh M.I., Pak A.O. (2008), Study of the mechanism of action of Scanpro additives on the structural and mechanical properties of gems, Modern directions of technology and mechanization of processes of processing and food production: A Collection of Scientific Works of Petro Vasylenko Kharkiv National University of Agriculture, 74, 146-153.

Rana P., Sharma S., Sharma R., Banerjee K. (2019), Apple pectin supported superparamagnetic $\left(\gamma-\mathrm{Fe}_{2} \mathrm{O}_{3}\right)$ maghemite nanoparticles with antimicrobial potency, Materials Science for Energy Technologies, 2(1), pp. 15-21, DOI: 10.1016/j.mset.2018.09.001.

Sanzharovskaya N.S., Khrapko O.P. (2017), Technology of jelly marmalade manufacture based on pectin extracts and herbal potions. International Research Journal, 10(64), pp. 95-98, DOI: $10.23670 / I R J .2017 .64 .055$.

Sicari V. (2017), Use of orange by-products (dry peel) as an alternative gelling agent for marmalade: Evaluation of antioxidant activity and inhibition of HMF formation during production different storage temperature, Journal of Food Processing and Preservation, 42(2), e13429, DOI:10.1111/jfpp.13429.

Silva C.E.F., Abud A.K.S. (2017), Tropical fruit pulps: processing, product standardization ands (m main control parameters for quality assurance. Brazilian Archives of Biology and Technology, 60, pp. 1-12. https://doi.org/10.1590/1678-4324-2017160209.

Shaaban H.A., El-Said A.N.M., Nagib A.I. (2020), Dates utilization to process some new dietary product (marshmallow and sheets) and their acceptability evaluation, Asian Journal of Biotechnology, 12(1), pp. 47-55, DOI: 10.3923/ajbkr.2020.47.55.

Stabnikova O., Marinin A., Stabnikov V. (2021), Main trends in application of novel natural additives for food production, Ukrainian Food Journal, 10(3), pp. 524-551.

Tsykhanovska I. (2019), Development of molded jelly marmelad technology with the introduction of food additive Magnetofood, Bulletin of the National Technical University "KhPI". Ser.: New Solutions in Modern Technologies, Kharkiv: NTU "KhPI", 10(1335), pp. 109-120, DOI: $10.20998 / 2413-4295.2019 .10 .14$.

Tsykhanovska I., Alexandrov O., Evlash V., Gontar T., Lazareva T. (2016), Food additive Magnetofood. Patent UA 126502.

Tsykhanovska I., Yevlash V., Khamitova B., Kaida N. (2019a), Influence of the Magnetofood food supplement on the structural and mechanical properties of molded fruit jelly with various structure-forming agents. Bulletin of the National Technical University "KhPI". Ser.: New Solutions in Modern Technologies, Kharkiv: NTU "KhPI", 5(1330), pp. 75-186, DOI:10.20998/2413-4295.2019.05.23.

Tsykhanovska I., Yevlash V., Alexandrov A., Khamitova B., Svidlo K., Nechuiviter O. (2019b), Forming the structure of whipped desserts when introducing the food additive «Magnetofood» to their formulation, Eastern-European Journal of Enterprise Technologies, 2, 11(98), pp. 45-55, DOI: 10.15587/1729-4061.2019.161855.

Verma D., Gulati N., Kaul S., Mukherjee S., Nagaich U. (2018), Protein based nanostructures for drug delivery, Journal of Pharmaceutics, Article ID 9285854, DOI: 10.1155/2018/9285854.

Yang Y., Zhang G., Hong Y., Gua Z., Fang F. (2013), Calcium cation triggers and accelerates the gelation of high methoxyl pectin, Food Hydrocolloids, 32(2), pp. 228-234, DOI: 10.1016/j.foodhyd.2013.01.003. 